\title{
Management of Oligodendroglioma Patients
}

\author{
Muhammad Miftahussurur, Ugroseno and Amie Asrhariati \\ Department of Internal Medicine, Faculty of Medicine, Universitas Airlangga, Dr. Soetomo Teaching Hospital, Jl. Prof \\ Moestopo 47, Surabaya 60132, Indonesia \\ apji@fk.unair.ac.id
}

Keywords: Brain tumor, Chemotherapy, Mild stage, Oligodendroglioma, Oligodendroglioma therapy.

\begin{abstract}
Oligodendroglioma is a neuroepithelial tissue tumor of glioma type and responds well to chemotherapy. Oligodendroglioma tends to invade leptomeninges. Further metastases of cerebrospinal fluid occur in 1-2\% of cases. The prognosis of patients with oligodendroglioma is varied, depending on the grade they are experiencing. Progression to anaplasia may occur, even though the frequency is lower than astrocytoma. The diagnosis of oligodendroglioma is based on light microscope examination, and is often difficult to distinguish from astrocytoma. A case of a low-grade oligodendroglioma patient is reported. Special attention is required in this grade, as it can progress slowly but progressively with manifestations only in the form of partial seizures that occur for years. The diagnosis is based on several clinical, radiological signs and is supported by anatomical pathology examination. This patient was given temozolomide (TMZ) chemotherapy for 6 cycles and radiotherapy after resection surgery. The patient survived until 28 months without tumor residue or a new tumor.
\end{abstract}

\section{INTRODUCTION}

Oligodendroglioma is a tumor derived from or its histological description describes its oligodendrocytes or precursors (DeAngelis, 2001). First discovered by Bailey and Cushing in 1926, this tumor is generally found in 2-5\% of all primary brain tumors, and it is the third most frequent of all glioma subtypes (4-15\%). Even though oligodendroglioma incidence is increasing, its prevalence is relatively rare, with less than 4 cases per 1,000,000 population/year (Engelhard et al., 2003; Knox, 2004; Koeller and Rushing, 2005).

Oligodendroglioma diagnosis is based on light microscopy examination using hematoxylin-eosin staining. It is often difficult to distinguish from astrocytoma as many oligodendrogliomas also contain an astrocytic component; therefore it is called oligoastrositoma. To date, there has been no immunohistochemical marker that can help make the diagnosis. Nevertheless, current oligodendroglioma diagnosis is easier due to more advanced brain imaging through magnetic resonance imaging (MRI) (Engelhard et al., 2003; Cha et al., 2005).

Oligodendroglioma is a glioma subtype that responds well to chemotherapy (Engelhard et al., 2003). Nitrosurea-based chemotherapy, particularly
PCV

[procarbazine,

lomustine

(cyclohexylchloroethylnitrosourea; CCNU) and vincristine] has long been recognized and most often used as the primary choice for oligodendroglioma and is given before and after radiotherapy (Stupp et al., 2006). Temozolomide (TMZ) has been developed as an alternative medicine since the 1990s. TMZ is an oral DNA methylating agent with good bioavailability, good anti-tumor activity and penetration to the brain (Xuan et al., 2004; Corsa et al., 2006).

Oligodendroglioma patients' prognosis varies. The prognosis in patients with low-grade oligodendroglioma (I-II) ranges from 3.5 to $16.7 \%$, while the 5-year survival rate varies between 38 $83 \%$. Progression to anaplasia may occur, even though the frequency is lower than astrocytoma (Deangelis, 2004).

\section{CASE}

A man, Mr. S, aged 42 years old, Javanese, privatesector employee, from Bontang, East Borneo, was admitted to hospital with a brain tumor complaint after having surgery 1 month before with planned chemotherapy. 
The patient had undergone brain tumor surgery removal 1 month before with suspicion of residual tumor after surgery. He was treated temporarily by 3 x $100 \mathrm{mg}$ of Dilantin and $3 \times 150 \mathrm{mg}$ of Oxcarbazepine (Trileptal). He often had seizures throughout the body one year before diagnosis. The seizures occurred for about 10 minutes every 3 months. He also had complaints of headaches for the last 3 months, particularly the left side of his head, with no vertigo, nausea, vomiting, visual impairment, weakness or tingling or thickness in some parts of the body. He had no hypertension history or family members with similar illnesses.

Physical examination found the patient's general condition to be moderate, and was compos mentis. Weight $69.4 \mathrm{~kg}$, height $167 \mathrm{~cm}$, blood pressure $100 / 70 \mathrm{mmHg}$, heart rate 80 beats/min, axillary temperature $36.7^{\circ} \mathrm{C}$, respiratory rate $20 \mathrm{breaths} / \mathrm{min}$. The head and neck examinations showed no anemia, jaundice, cyanosis or tightness, or enlarged lymph nodes. A chest examination found symmetrical movement and no visible asimetric chest movement. Heart examination found a single heart sound without additional sounds. A lung examination found vesicular breathing sounds without rhonchi. The liver and lien was not palpable, no abdominal mass were found, and bowel sounds is normal. Extremity examination found no anemia or edema.

Neurological examination found normal motor power of the left and right extremities. No impairment was found in sensory examination. The meningeal sign test did not find a stiff neck, Kernig's sign or Brudzinski I \& II. Cranial nerve examination found an isochoric pupil $4 / 4 \mathrm{~mm}$ with a normal positive light reflex. No decreased reflex was found to reflect either BPR, KPR, TPR or APR. There was a positive sign in the pathological reflex examination of the right-side Babinski, where as the variance are - / -, CV / ANS dbN.

The laboratory test showed $\mathrm{Hb} 14.6 \mathrm{~g} \%$, PCV $41.2 \%$, leucocytes $10,900 \mathrm{~K} / \mathrm{uL}$, platelets $164,000 / \mathrm{mml}$, sedimentation rate $5 \mathrm{~mm} /$ hour, random glucose $81 \mathrm{mg} / \mathrm{dl}$, AST $26 \mathrm{U} / \mathrm{L}$ and ALT 22 $\mathrm{U} / \mathrm{L}$, alkaline phosphatase $395 \mathrm{U} / \mathrm{L}$, albumin 6.0 $\mathrm{mg} \%$, uric acid $4.4 \mathrm{mg} / \mathrm{dl}$, BUN $13.5 \mathrm{mg} / \mathrm{dl}$, serum creatinine $1.2 \mathrm{mg} / \mathrm{dl}, \mathrm{Na} 143 \mathrm{mmol} / \mathrm{L}$ and potassium $4.0 \mathrm{mmol} / \mathrm{L}$. The supporting thoracic photo examination (07-07-2007) showed normal Cor and Pulmo. The CT scan of preoperative head without axial incision contrast with left temporo parietal marker (09-07-2009) showed a hypodense area as much as $3.36 \times 2.89 \mathrm{~cm}$ in the left temporoparietal cortex with indistinct edges. The mass starts to be visible in image 4 (sp-111) until image 9 (sp-71).
There was no mass/midline shifting/abnormal calcification effect. Girus, sulci, cisterna and ventricular system all gave the conclusions of a lower left temporoparietal astrocytoma impression.

The anatomical pathology examination (No. P357/2007) (July 16, 2007) found tissue with a uniform cell population, consisting of uniform round cells without pleomorfi/atypical signs. There were several small grains of mercury. Oligodendroglioma stage I-II. The MRI examination after surgery (July $23,2007)$ showed a little bleeding near the mass in the left temporoparietal, minimal subdural hemorrhage with adjacent air in the left temporoparietal area at the lateral mass with moderate effect. Based on the data above, the patient was diagnosed with post-operative oligodendroglioma stage I-II. Chemotherapy and radiotherapy were planned as adjuvant therapy.

Since oligodendroglioma is a glioma subtype that responds well to chemotherapy and the remaining tumor, we planned TMZ chemotherapy and radiotherapy. We assessed treatment and cure results and were wary of side-effects.

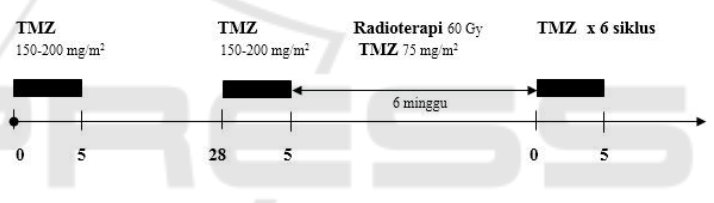

Figure 1: Chemotherapy and radiotherapy planning.

After the first cycle of chemotherapy, the patient's general condition was good (Karnofsky criteria > 70 and ECOG 1). BW $69.4 \mathrm{~kg}$, height 167 $\mathrm{cm}$, body surface area (BSA) $1.75 \mathrm{~m}^{2}$. TMZ chemotherapy of $300 \mathrm{mg}$ cycle I was conducted for 5 days consecutively.

After the $2^{\text {nd }}$ cycle of chemotherapy, the patient had no complaint with a good general condition (Karnofsky criteria $>70$ and ECOG 1). BW $69.4 \mathrm{~kg}$, height $167 \mathrm{~cm}$, BSA $1.75 \mathrm{~m}^{2}$. Hb $14.5 \mathrm{~g} \%$, PCV $44.1 \%$, leukocytes $4,300 \mathrm{~K} / \mathrm{uL}$, platelets $197,000 / \mathrm{mml}$, blood sedimentation rate $20 \mathrm{~mm} / \mathrm{hour}$. ESO grade 0 . TMZ chemotherapy of $300 \mathrm{mg}$ cycle II was conducted for 5 days consecutively. On the $6^{\text {th }}$ day after chemotherapy, the patient's was given radiotherapy with a dose of $60 \mathrm{~Gy}$ was performed for 6 weeks with a combination of TMZ $75 \mathrm{mg} / \mathrm{m}^{2}$ chemotherapy to improve sensitivity during radiotherapy.

After the 3rd cycle of chemotherapy, the patient had no complaint with a good general condition (Karnofsky criteria > 70 and ECOG 1). BW 69.4 kg, height $167 \mathrm{~cm}$, BSA $1.75 \mathrm{~m}^{2}$. Hb $15.1 \mathrm{~g} \%$, PCV 
$45 \%$, leukocytes $5,900 \mathrm{~K} / \mathrm{uL}$, platelets $176,000 / \mathrm{mml}$, random glucose $88 \mathrm{mg} / \mathrm{dl}$, AST $29 \mathrm{U} / \mathrm{L}$ and ALT 25 $\mathrm{U} / \mathrm{L}$, alkaline phosphatase $232 \mathrm{U} / \mathrm{L}$, uric acid 7.4 $\mathrm{mg} / \mathrm{dl}$, BUN $13 \mathrm{mg} / \mathrm{dl}$, serum creatinine $1.3 \mathrm{mg} / \mathrm{dl}$, $\mathrm{Na} 145 \mathrm{mmol} / \mathrm{L}$ and potassium $3.5 \mathrm{mmol} / \mathrm{L}$. ESO grade 0 . TMZ chemotherapy of $300 \mathrm{mg}$ cycle III was conducted for 5 days consecutively.

After the $4^{\text {th }}$ cycle of chemotherapy, the patient had no complaint with a good general condition (Karnofsky criteria > 70 and ECOG 1). BW $72 \mathrm{~kg}$, height $167 \mathrm{~cm}$, BSA $1.86 \mathrm{~m}^{2}$. Hb $15.6 \mathrm{~g} \%$, PCV $45 \%$, leucocytes $4,500 \mathrm{~K} / \mathrm{uL}$, platelets $176,000 / \mathrm{mml}$, random glucose $88 \mathrm{mg} / \mathrm{dl}$, AST $29 \mathrm{U} / \mathrm{L}$ and ALT 25 $\mathrm{U} / \mathrm{L}$, alkaline phosphatase $232 \mathrm{U} / \mathrm{L}$, urine $7.4 \mathrm{mg} / \mathrm{dl}$, BUN $13 \mathrm{mg} / \mathrm{dl}$, serum creatinine $1.3 \mathrm{mg} / \mathrm{dl}, \mathrm{Na} 145$ $\mathrm{mmol} / \mathrm{L}$ and potassium $3.5 \mathrm{mmol} / \mathrm{L}$. ESO grade 0 . TMZ chemotherapy of $320 \mathrm{mg}$ cycle IV was conducted for 5 days consecutively.

The results of head MRI, three weeks after the $4^{\text {th }}$ cycle of chemotherapy, were as follows:

1. Encephalomalaceal cyst in the left parietal surgical bed

2. Conventional MRI: normal

3. MRA showed decreased vascularization in the area around the surgical bed compared to the contralateral side.

4. MR perfusion showed no increased $\mathrm{rCBV}$ around the surgical bed, but MR spectroscopy showed increased choline metabolites with high choline/creatine ratios. There was no invisible recurrence mass with conventional MRI.

5. A retention cyst was found at the base of maxillary sinus D

Conclusion: conventional MRI and normal MRA, MR spectroscopy showed an increased choline ratio (could be false). Suggestion: repeat MRI in 3 months.

After the $5^{\text {th }}$ cycle of chemotherapy, the patient had no complaint with a good general condition (Karnofsky criteria > 70 and ECOG 1). BW $72 \mathrm{~kg}$, height $167 \mathrm{~cm}$, BSA $1.86 \mathrm{~m}^{2}$. Hb $15.5 \mathrm{~g} \%$, PCV $45 \%$, leucocytes $6,800 \mathrm{~K} / \mathrm{uL}$, platelets $157,000 / \mathrm{mml}$, AST $29 \mathrm{U} / \mathrm{L}$ and ALT $43 \mathrm{U} / \mathrm{L}$, and uric acid 5.6 $\mathrm{mg} / \mathrm{dl}$. ESO grade $0 . \mathrm{TMZ}$ chemotherapy of $320 \mathrm{mg}$ cycle $\mathrm{V}$ was conducted for 5 days consecutively.

After the $6^{\text {th }}$ cycle of chemotherapy, the patient had normal CXR and ultrasonography. MRI found encephalomalacia in the area of the former left temporoparietal surgery, with neither tumor residue nor new tumors. The retention cyst was based on the right maxillary sinus.

The patient had no complaint with a good general condition (Karnofsky criteria > 70 and ECOG 1). BW $72 \mathrm{~kg}$, height $167 \mathrm{~cm}$, BSA $1.86 \mathrm{~m}^{2}$.
Hb $15 \mathrm{~g} \%$, PCV $42 \%$, leucocytes 7,300 K/uL, thrombosis 163,000/mml, AST $34 \mathrm{U} / \mathrm{L}$ and ALT 45 $\mathrm{U} / \mathrm{L}$, uric acid $5.1 \mathrm{mg} / \mathrm{dl}$. ESO grade 0 .

TMZ chemotherapy of $320 \mathrm{mg}$ cycle VI was conducted for 5 days consecutively.

After that, the patient had normal CXR and ultrasonography. MRI found encephalomalacia in the area of the former left temporoparietal surgery. There was no tumor residue nor new tumors. The patient survived until 28 months without complaint.

\section{DISCUSSION}

Brain tumors are classified according to their constituent cell type and nervous system structure, as seen in Table 1. Oligodendroglioma is a neuroepithelial tissue tumor (Chantler, 2004).

Table 1: Brain Tumor Classification.

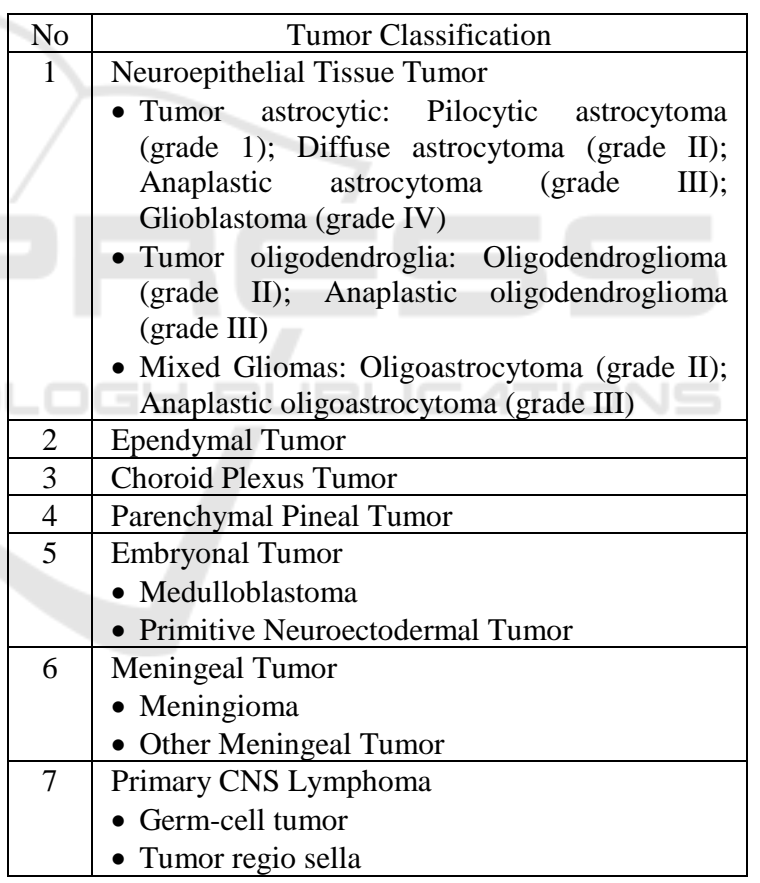

Source: Chantler, 2004

Oligodendroglioma can occur at any age, but its incidence usually reaches its peak in two age groups of 6-12 years and 35-44 years (Engelhard et al., 2003; Koeller and Rushing, 2005). Men are more frequently affected than women, with a 1:1-2:0 ratio (Knox, 2004; Stupp et al., 2006).

This male patient was 42 years old, and thus included in the most highly affected sex and age groups for oligodendroglioma. 
Clinical presentation seen in oligodendroglioma patients usually lasts for about 5 years because it grows slowly (Koeller and Rushing, 2005). Most patients have seizures $(35-85 \%)$. The types of seizure include general, simple partial, complex partial or a combination of both. A new diagnosis is known after acute bleeding, or several years after treatment with unidentified seizures. Spontaneous hemorrhage often results from blood vessel thinning (DeAngelis, 2001). Oligodendroglioma often causes seizures and bleeding tendency compared to astrocytoma, with a $10 \%$ incidence (Deangelis, 2004). Other symptoms may include headache (40\%), mental state change $10 \%$ ), vertigo, nausea, visual impairment and limb weakness (5-15\%) (Engelhard et al., 2003; Koeller and Rushing, 2005).

This patient had seizure complaints of the whole body for one year and headaches for 3 months before being diagnosed. There were no signs of bleeding, vertigo, nausea, vomiting, visual impairment, weakness or tingling or thickness in some parts of the body.

Anatomically, oligodendroglioma may occur in the oligodendrocyte site. Most primary sites are in the frontal $(55 \%)$, followed by temporal $(47 \%)$, parietal $(20 \%)$, occipital $(4 \%)$, cerebellar $(3 \%)$ and spinal $(1 \%)$ regions. The location of tumor growth (tendency in the gray matter cortex) is associated with seizures as the most common symptoms (Koeller and Rushing, 2005).

In this patient, oligodendroglioma was found in the left temporoparietal cortex (second and third largest after the frontal region).

The anatomic pathology examination as a gold standard of oligodendroglioma patients has a medium and regular (monotonic and uniform) cellular appearance, rounded core surrounded by peripheral hyperchromatic (perinuclear halos) which under hematoxylin-eosin staining is called "friedegg appearance", and sometimes it shows blood vessel branches and calcification, the so-called "honeycomb" or "chicken-wire" (Perry et al., 1999; Knox, 2004; Koeller and Rushing, 2005).

In this patient, the result of tissue PA was a uniform cell population, consisting of uniform round cells without pleomorfi/atypical signs, with small grains of mercury. Therefore, he was diagnosed with oligodendroglioma.

Brain tumors, based on their aggressiveness, are classified into 4 grades. Grades I and II are referred to as low grade, while grades III and IV are referred to as high grade. High-grade tumors tend to grow very quickly and require multi-modality therapy (surgery, radiation and/or chemotherapy).
Oligodendroglioma is classified as low grade (I-II) if there is no histologic feature of anaplasia, such as high cellularity, nuclear pleomorphism, mitotic, figures, endothelial proliferation and necrosis (Engelhard et al., 2003).

This patient had no histology anaplasia, either in the form of high cellularity, nuclear pleomorphism, mitotic, figures, endothelial proliferation or necrosis; therefore, it was classified as oligodendroglioma grade I-II.

Low-grade oligodendroglioma therapy requires special attention, as it can progress slowly but progressively with manifestations of only partial seizures occurring over the years. Therapy includes surgery, radiotherapy and chemotherapy. Resection surgical therapy is a primary therapy, especially if it is easily accessible and may not cause neurological damage (Xuan et al., 2004). It aims to reduce the decompression effects, radiotherapy needs, extend survival and evaluate the classification and tumor grade. In most cases, the outcome is largely dependent on the extent of the operation (Jacob et al., 2002; Hartmann and Deimling, 2005).

In this patient, total surgical resection was performed because the location was easy to reach (in the temporoparietal cortex), and continued with tumor classification and grade with oligodendroglioma result (grade I-II).

The systematics of chemotherapy procedure in cancer is a definite diagnosis (PA result), clear stage (determining treatment mode, prognosis and evaluation of treatment outcomes), and a good general condition measured by performance status. The most commonly used assessment tools are Eastern Cooperative Oncology Group (ECOG) and Karnofsky scale (Table 1). Performance status may be used to guide prognostic implications for certain types of malignancies such as brain and lung cancer (Chantler, 2004; Boediwarsono, 2009).

This patient was given chemotherapy after being diagnosed with oligodendroglioma (grade I-II) based on the PA result. The patient's general condition was good with Karnofsky > 70 and ECOG 0 (Table 2).

Table 2: Karnofsky and ECOG status performance.

\begin{tabular}{|c|l|c|l|}
\hline \multicolumn{2}{|c|}{ KARNOFSKY } & \multicolumn{2}{|c|}{ ECOG } \\
\hline Score & \multicolumn{1}{|l|}{ Interpretation } & Score & Interpretation \\
\hline $80-100$ & \begin{tabular}{l} 
Normal activities \\
and do not require \\
special assistance \\
without or with \\
\cline { 2 - 4 } \\
minimal \\
symptoms of the \\
disease.
\end{tabular} & 0 & $\begin{array}{l}\text { Full activity, } \\
\text { no } \\
\text { symptoms. }\end{array}$ \\
\hline
\end{tabular}




\begin{tabular}{|c|l|c|l|}
\hline $50-70$ & $\begin{array}{l}\text { Cannot work, but } \\
\text { can work at home } \\
\text { and are able to do } \\
\text { self-care, although } \\
\text { varying levels of } \\
\text { help are still } \\
\text { needed. }\end{array}$ & 2 & $\begin{array}{l}\text { Unable to } \\
\text { work, } \\
\text { ambulatory > } \\
50 \% \text { of daily } \\
\text { time. }\end{array}$ \\
\hline $10-40$ & $\begin{array}{l}\text { Unable to perform } \\
\text { self-care, require } \\
\text { short or long-term } \\
\text { care at the } \\
\text { hospital and } \\
\text { develop } \\
\text { progressive } \\
\text { illness. }\end{array}$ & $\begin{array}{l}\text { and time in } \\
\text { bed, limited } \\
\text { self-care. }\end{array}$ \\
\hline 0 & Death & $\begin{array}{l}\text { Completely } \\
\text { disabled, to } \\
\text { limited to } \\
\text { bed or chair, } \\
\text { unable to } \\
\text { perform self- } \\
\text { care. }\end{array}$ \\
\hline
\end{tabular}

Source: Chantler, 2004

Around $60-70 \%$ of oligodendroglioma patients respond with combination chemotherapy of procarbazine, lomustine (cyclohexylchloroethylnitrosourea; $\mathrm{CCNU}$ ) and vincristine (PCV) given in a 42-day cycle. Several other cytotoxic drugs are also reported to be sensitive such as melphalan, thiotepa, TMZ, paclitaxel (Taxol) and platinum-based regimens. The cause of sensitivity to chemotherapy remains unclear, suggesting that neoplastic cells in oligodendroglial derivatives are weak against the alkylating effects of cytotoxic chemotherapy, but cytotoxic chemotherapy exposure activates p53mediated cell death pathways (Perry et al., 1999). The use of alternatives to PCV began to be considered, given the majority of patients relapsed after 12-18 months and the onset of myelosuppression effects (Paleologos and Cairncross, 1999; Engelhard et al., 2003; Deangelis, 2004). TMZ is initially used primarily in anaplastic oligodendroglioma (grade 3-4) and recurrence with higher efficacy and tolerance, and it is considered a "rescue" therapy if it does not respond to PCV regimens (Stupp et al., 2006; Corsa et al., 2006; Katz et al., 2009). However, TMZ is currently used as the first-line in low-grade oligodendroglioma, particularly in patients with chromosome $1 \mathrm{p}$ and $19 \mathrm{q}$ deletions with a response of 70\% (Xuan et al., 2004; Kaloshi et al., 2007). The cytotoxicity effect of TMZ is by causing disruption to DNA repair by O6 methylation position of guanine. During replication, O6 methylguanine is paired with thymine, thus triggering an improper system of repair and causing damage to DNA strands, which in turn leads to growth and apoptotic disorders (Geiger et al., 2008). A study showed variability against response level to
TMZ as the second line after the PCV regimen (25$44 \%)$. These results indicate the importance of patient selection, particularly whether the patient suffers from "true" oligodendroglioma (Knox, 2004).

This patient was given TMZ $150-200 \mathrm{mg} / \mathrm{m}^{2}$ for 5 days as much as 6 cycles with increasing dose adjusted with BSA. We had not analyzed chromosome to find the existence of chromosome $1 p$ and $19 \mathrm{q}$ deletions.

Precautions for side-effects following chemotherapy should be considered (Boediwarsono, 2009). The most frequently reported TMZ sideeffects are nausea (53\%), vomiting $(42 \%)$, headache $(41 \%)$, fatigue (34\%) and diarrhea (16\%). Meanwhile, the hematological side-effects (grade 34) ranged from 4-19\% (Xuan et al., 2004).

Up to the 5th chemotherapy there were no any adverse events such as nausea, vomiting, diarrhea and haematological side effects obtained.

Radiotherapy is an option of post-operative therapy, particularly if there is a significant residual tumor after surgery found by imaging, or if there is aggression or pathologic features. Radiotherapy has been shown to be effective in stabilizing tumor progression and controlling complaints, with increased survival rates of 84 months versus 47 months without radiotherapy (Jacob et al., 2002). However, clinicians should note the toxic effects found after several years. Radiotherapy was administered postoperatively at $45-65$ Gy for 6 weeks (Brada, 1994; Perry et al., 1999; Hartmann and Deimling, 2005).

This patient was given radiotherapy of $60 \mathrm{~Gy}$ for 6 weeks due to suspicion of residual tumor after surgery based on MRI (there was a little bleeding near the mass in the left temporoparietal). After undergoing radiotherapy and TMZ chemotherapy, no new tumor residue and tumor was found up to 28 months and no toxic effects from radiotherapy were found.

Chemotherapy as the initial postoperative therapy is administered if there is a delay in radiotherapy or in high-risk patients with one or more poor prognostic factors such as age $\geq 40$, incomplete resection, neurological symptoms (generally persistent seizures) and progressivity in CT/MRI (Brainin et al., 2004).

Due to radiotherapy delay, this patient was given TMZ postoperative chemotherapy at a dose of 150$200 \mathrm{mg} / \mathrm{m}^{2}$.

Oligodendroglioma tends to invade leptomeninges. Further metastases of cerebrospinal fluid occur in $1-2 \%$ of cases. In addition, 
oligodendroglioma tends to spread outside the central nervous system compared with other gliomas, which spread in bone, lung, pleura and liver, particularly in patients with chromosome $1 \mathrm{p}$ and $19 q$ loss (Engelhard et al., 2003).

This patient underwent chest $\mathrm{x}$-ray, abdominal ultrasound and head MRI 3.5 years postoperative. The result did not show any tumor residue or new tumor.

Age $>40$ years is one of the bad prognostic factors, and this is related to the association between age and level of Glioma O6-methylguanine-DNA methyltransferase (Perry et al., 1999). Deletion of short arm chromosome 1 (1p) as much as 40-92\% and long arm chromosome arm 19 (19q) as much as $50-80 \%$ are associated with phenotype and recurrence duration after radiotherapy and/or chemotherapy. The chromosomal region is considered to have a tumor suppression gene that can block tumor development and/or progression (Brada, 1994; Deangelis, 2004; Katz et al., 2009).

This patient was $>40$ years old, but he had not undergone chromosomal analysis to look for chromosome $1 \mathrm{p}$ and $19 \mathrm{q}$ deletions.

\section{SUMMARY}

The diagnosis of oligodendroglioma is based on light microscope examination, and is often difficult to distinguish from astrocytoma. A case of a lowgrade oligodendroglioma patient has been reported. Special attention is required in this grade, as it can progress slowly but progressively with manifestations only in the form of partial seizures that occur for years. The diagnosis is based on several clinical, radiological signs and is supported by anatomical pathology examination. This patient was given temozolomide (TMZ) chemotherapy for 6 cycles and radiotherapy after resection surgery. The patient survived until 28 months without tumor residue or new tumors.

\section{REFERENCES}

BOEDIWARSONO 2009. Update on medical management of cancer in Indonesia : prevention, early detection, curative treatment and palliative care to cure often, to relief and to comfort always. Surabaya hematologi onkologi medik update-VII. Surabaya

BRADA, M. 1994. Tumors of the central nervous system, Springer-Verlag.
BRAININ, M., BARNES, M., BARON, J. C., GILHUS, N. E., HUGHES, R., SELMAJ, K., WALDEMAR, G. \& GUIDELINE STANDARDS SUBCOMMITTEE OF THE, E. S. C. 2004. Guidance for the preparation of neurological management guidelines by EFNS scientific task forces--revised recommendations 2004. Eur J Neurol, 11, 577-81.

CHA, S., TIHAN, T., CRAWFORD, F., FISCHBEIN, N. J., CHANG, S., BOLLEN, A., NELSON, S. J., PRADOS, M., BERGER, M. S. \& DILLON, W. P. 2005. Differentiation of low-grade oligodendrogliomas from low-grade astrocytomas by using quantitative blood-volume measurements derived from dynamic susceptibility contrast-enhanced MR imaging. AJNR Am J Neuroradiol, 26, 266-73.

CHANTLER, M. L. 2004. Introduction and approach to oncology, Lippincott Williams \& Wilkins Publishers.

CORSA, P., PARISI, S., RAGUSO, A., TROIANO, M., PERRONE, A. \& AL, E. 2006. Temozolomide and radiotherapy as first-line treatment of high-grade gliomas. Tumori, 92, 299-305.

DEANGELIS, L. M. 2001. Brain tumors. $N$ Engl J Med, 344, 114-23.

DEANGELIS, L. M. 2004. Neurological tumors. In: Manual of clinical oncology.

ENGELHARD, H. H., STELEA, A. \& MUNDT, A. 2003. Oligodendroglioma and anaplastic oligodendroglioma: clinical features, treatment, and prognosis. Surg Neurol, 60, 443-56.

GEIGER, G. A., FU, W. \& KAO, G. D. 2008 Temozolomide-mediated radiosensitization of human glioma cells in a zebrafish embryonic system. Cancer Res, 68, 3396-404.

HARTMANN, C. \& DEIMLING, A. V. 2005. Oligodendrogliomas: impact of molecular genetics on treatment. Neurology india, 53, 140-8.

JACOB, R., JYOTHIRMAYI, R., DALAL, Y., NAMBIAR, U., RAJAN, B. \& NAIR, M. K. 2002. Oligodendroglioma: clinical profile and treatment results. Neurol India, 50, 462-6.

KALOSHI, G., BENOUAICH-AMIEL, A., DIAKITE, F., TAILLIBERT, S., LEJEUNE, J., LAIGLEDONADEY, F., RENARD, M. A., IRAQI, W., IDBAIH, A., PARIS, S., CAPELLE, L., DUFFAU, H., CORNU, P., SIMON, J. M., MOKHTARI, K., POLIVKA, M., OMURO, A., CARPENTIER, A., SANSON, M., DELATTRE, J. Y. \& HOANG-XUAN, K. 2007. Temozolomide for low-grade gliomas: predictive impact of $1 \mathrm{p} / 19 \mathrm{q}$ loss on response and outcome. Neurology, 68, 1831-6.

KATZ, A., CALABRICH, A., DOS SANTOS FERNANDES, G. \& SAKIS NOVIS, Y. A. 2009. Complete Radiologic Response in an Anaplastic Oligodendroglioma Treated with Temozolomide and Bevacizumab. Case Rep Oncol, 2, 57-60.

KNOX, S. K. 2004. Intracranial tumors, Lippincott Williams \& Wilkins Publishers.

KOELLER, K. K. \& RUSHING, E. J. 2005. From the archives of the AFIP: Oligodendroglioma and its 
variants: radiologic-pathologic correlation. Radiographics, 25, 1669-88.

PALEOLOGOS, N. A. \& CAIRNCROSS, J. G. 1999. Treatment of oligodendroglioma: an update. Neuro Oncol, 1, 61-8.

PERRY, J. R., LOUIS, D. N. \& CAIRNCROSS, J. G. 1999. Current treatment of oligodendrogliomas. Arch Neurol, 56, 434-6.

STUPP, R., HEGI, M. E., VAN DEN BENT, M. J., MASON, W. P., WELLER, M., MIRIMANOFF, R. O., CAIRNCROSS, J. G., EUROPEAN ORGANISATION FOR, R., TREATMENT OF CANCER BRAIN, T., RADIOTHERAPY, G. \& NATIONAL CANCER INSTITUTE OF CANADA CLINICAL TRIALS, G. 2006. Changing paradigms-an update on the multidisciplinary management of malignant glioma. Oncologist, 11, 165-80.

XUAN, H. K., CAPELLE, L., KUJAS, M., TAILLIBERT, S., DUFFAU, H. \& AL, E. 2004. Temozolomide as initial treatment for adults with low-grade oligodendrogliomas or oligoastrocytomas and correlation with chromosome $1 \mathrm{p}$ deletions. J Clin Oncol 22, 3133-38. 